Working Paper

Research Department Federal Reserve Bank of Minneapolis 
Federal Reserve Bank of Minneapolis

Research Department

\title{
Valuation Equilibria With Clubs
}

\author{
Harold L. Cole and Edward C. Prescott*
}

Working Paper 524

March 1994

*Cole, Federal Reserve Bank of Minneapolis; Prescott, University of Minnesota and the Federal Reserve Bank of Minneapolis. This research was in part supported by the National Science Foundation. The views expressed herein are those of the authors and not necessarily those of the Federal Reserve Bank of Minneapolis or the Federal Reserve System. 


\section{Introduction}

Many human interactions in which economists are interested involve agents voluntarily forming associations in order to undertake joint activities. Important examples of such organizations are households and firms. Other examples include organizations formed to provide some set of local public goods such as a condominium association. There has developed an extensive literature on matching models which analyzes the equilibria of job-worker and husband-wife matching models, as well as an extensive literature on associations which provide local public goods, commonly referred to as clubs. ${ }^{1}$ In these literatures cooperative and noncooperative game theoretic tools have been the predominant mode of analysis. In this paper we show that general equilibrium analysis with linear price systems can be extended to quite general environments in which associations are being endogenously formed. The range of possible activities that we can allow the associations in our model to undertake is quite broad, encompassing both consumption and production activities. The technology which is available to these association can depend on characteristics of its membership, and can deal with jointness of activities within the association. We do require any possible association to be small relative to the large number of people.

We will refer to these associations as clubs since they fall within the spirit of the club literature. We use the term club type to refer not only to the relevant characteristics of the membership but also the nature of the economic activities undertaken, in particular to the net output vector of the club. One complication of our environment is that the set of possible club types is large and membership is discrete. We deal with the first problem by considering each separate club

\footnotetext{
${ }^{1}$ For the cooperative and noncooperative literatures on matching models standard references are Roth and Sotomayor (1990) and Osborne and Rubinstein (1990), respectively. In the club literature, the standard model is one in which there is an excludable local public good to be consumed with congestion and a private consumption good. Standard references for this literature are Cornes and Sandler (1986) or Sandler and Tschirhart (1980).
} 
type as a separate commodity, and having, possible, a continuum of differentiated commodities. In order to deal with the problem of discrete membership, we follow Mas-Colell (1975), Hart (1979), and Jones (1984) in using the space of signed measures as our commodity space. Another complication with our environment is that in club environments where there is a deterministic commodity space, and people maximize expected utility, there typically exist gains from trade in randomized contracts, due to the indivisibility in agents' consumption sets. In order to deal with this problem, we follow Prescott and Townsend (1984a, 1984b) and Rogerson $(1984,1988)$, and consider consumption possibility sets that consist of probability distributions over final consumption bundles.

Our choice of commodity space greatly simplifies competitive analysis of our environment. While agents' possible choices over clubs are not convex, their possible choices over random contracts which specify the probability of membership, are. Since the membership in any one club is small relative to size of the population, the aggregate production technology is a convex cone. Additionally, since we will restrict ourselves to economies in which there will be a continuum of agents, but only a finite number of types, the convexity of our economies permits us to consider only type identical allocations; each agent of a given type chooses the same point in the commodity space. As a result virtually all the classical general equilibrium results for convex economies with a finite set of agents can be extended to our club economies. The standard results on the equivalence of core and competitive allocations with a continuum of agents can also be shown to hold.

This use of a commodity space which allows for trades in randomized contracts differentiates our work from previous work on market based decentralizations of traditional club economies such as in Scotchmer (1985) and Scotchmer and Wooders (1987). Furthermore, unlike previous decentralizations of economies with externalities, such as Lindahl's (1919) and Foley (1970), where the commodity space included individual specific commodities, the decentralization that we consider is anonymous and markets are thick. 
The remainder of the paper is divided into two sections. In the first we analyze a simple two sex matching model in order to illustrate how to represent the model environment as a economy in the classical general equilibrium sense-that is one with no externalities. We show that a commodity space that allows for trade in randomized contracts is needed and that permitting randomization can lead to substantially different equilibrium allocations relative to the set equilibria where the commodity space only allowed for deterministic exchanges. In the next section we consider a much more general matching model and show how the standard results in general equilibrium theory can be readily extended. Since one seems to observe a great preponderance of methods of gambling over wealth transfers relative to lotteries over final consumption allocations, we were motivated in this section to also consider an alternative decentralization of our environment. In this alternative decentralization there are gambles over value transfers in the first stage, and a standard competitive economy in the second where all the trades are deterministic exchanges. We show that the set of equilibrium allocations for the two decentralizations are equivalent.

\section{A Prototype Environment With Clubs}

In this section we consider a simple model of household formation which is taken from Cole, Mailath, and Postlewaite (1993). ${ }^{2}$ We show how, through a suitable definition of the commodity space, this structure can be studied using valuation equilibrium theory with its single budget constraint and linear valuation or pricing function. We use this example to explain why within matching models a commodity space which includes randomized allocations is appropriate. This is

\footnotetext{
${ }^{2}$ Cole, Mailath, and Postlewaite actually consider a somewhat more elaborate model than we discuss here, and analyze it using both cooperative and noncooperative tools, as well as considering a deterministic market based decentralization with a much smaller commodity space than we do, but with nonlinear prices. One of their key results is that the equilibrium allocations of a natural contracting game is also the competitive equilibrium allocations. One key restriction on the set of models that they consider is that the number of females is equal to the number of males.
} 
done by considering a simple example and showing that under a deterministic decentralization there are mutually advantageous gains from entering into trade in randomized contracts. We then formally present a valuation equilibrium model of this simple matching environment, and show that the welfare theorems apply and that a competitive equilibrium exists when the commodity space allows for trade in randomized contracts. We then develop the implications of the first welfare theorem and the connection between planner's problems and equilibrium allocations in convex economies to develop an algorithm for computing all competitive equilibria of the protype economy. Finally, we show that the properties of this equilibrium allocation differ substantially from those in an economy without random contracts.

\section{The Environment}

There is a continuum of people. They are either of two types, which we will refer to as male or female, and which we will denote by $s \in\{f, m\}$. When referring to an agent of type $s$, we will use $s^{\prime}$ to denote the agent's opposite sex. The measure of persons having type $s$ is given by $\lambda_{\delta}>0$. There are two types of goods in the model: a personal consumption good and a club consumption good. A matched pair of agents of the opposite sex can consume both a pair-specific public good or club good, and individually, the personal consumption good. Agents can be matched with just one agent of the opposite sex. Unmatched agents can consume only the personal consumption good. People are endowed with the personal consumption good, and $\omega_{\mathbf{s}}$ denotes his or her endowment level. We assume that there is a production technology for converting one unit of the personal consumption good into half a unit of the club good.

The underlying consumption possibility set is $\mathrm{A} \times \mathrm{B}$, where $\mathrm{A}$ is the set of feasible personal consumptions and B the set of feasible pair or club consumptions. In this section, A will be $\mathbf{R}_{+}$and 
B either the interval $\left[0, b_{\max }\right]$ or a finite subset of this interval that includes zero. Preferences are identical for all people and are given by

$$
\text { (1.1) } \mathrm{E}\{\mathrm{u}(\mathrm{a})+\mathrm{v}(\mathrm{b})\}
$$

where $\mathrm{u}$ and $\mathrm{v}$ are defined on the positive real numbers and are assumed to be strictly concave, differentiable functions. Further, $\mathrm{u}^{\prime}(0)=\infty, \mathrm{v}$ bounded, $\mathrm{v}(0)=0$, and $\mathrm{v}^{\prime}(0)$ finite.

\section{Valuation Equilibrium Without Random Contracts}

To apply valuation equilibrium analysis, the balance condition for feasibility must depend only on the sum of the individuals' commodity vectors. Feasibility requires that the number of males consuming any given nonzero level of the club good must be equal to the number of females consuming that level. Thus, we index the club good by sex in order to distinguish between the sex of the person consuming a particular level of the club good. Further, since this equality must hold for every level of the club good, we treat every level of $b$ for each sex as a different commodity. These considerations, following Mas-Colell (1975), lead us to use the commodity space L = $\mathbf{R} \times \mathbf{M}(\mathrm{B}) \times \mathrm{M}(\mathrm{B})$, where $\mathrm{M}(\mathrm{B})$ denotes the set of signed measures on the Borel sigma algebra of $\mathrm{B}$. An element of $L$ is the triplet $\left(x_{0}, x_{f}, x_{m}\right)$. The element $x_{0}$ is the personal consumption good while the elements $x_{3}$ are signed measures of consumptions of the club goods of which there can be a continuum. In the case that the set of club consumptions is finite, the $x_{s}$ are finite dimensional vectors.

With this commodity space there is a fundamental indivisibility in the consumption possibility set. An individual can consume one and only one level of the club good. A person of type $s$ has the consumption possibility set

(1.2) $\mathrm{X}_{\mathrm{s}}=\left\{\mathrm{x} \in \mathrm{L}_{+}: \mathrm{x}_{\mathrm{s}}(\cdot) \in\{0,1\}, \mathrm{x}_{\mathrm{s}^{\prime}}=0\right\}$ 
the utility function

$$
\mathrm{U}_{\mathrm{s}}(\mathrm{x})=\mathrm{u}\left(\mathrm{x}_{\mathrm{o}}\right)+\int \mathrm{v}(\mathrm{b}) \mathrm{dx_{ \textrm {s } }}
$$

and his or her endowment $e^{s}=\left(\omega_{s}, 0,0\right) \in L$.

Our numeraire good is the personal consumption good. A pricing system p is a pair of bounded measurable functions $\mathrm{p}_{\mathrm{f}}$ and $\mathrm{p}_{\mathrm{m}}$ which map from $\mathrm{B}$ to $\mathrm{R}$, where $\mathrm{p} \cdot \mathrm{x}=\mathrm{x}_{\mathrm{o}}+\int \mathrm{p}_{\mathrm{f}}(\mathrm{b}) \mathrm{x}_{\mathrm{f}}(\mathrm{db})+$ $\int \mathrm{p}_{\mathrm{m}}(\mathrm{b}) \mathrm{x}_{\mathrm{m}}(\mathrm{db})$. An individual's budget constraint under this pricing system is $\mathrm{p} \cdot \mathrm{x} \leq \mathrm{p} \cdot \mathrm{e}$. Clearly given our linear production technology if there are to be zero profits in equilibrium $p_{f}(b)+p_{m}(b) \leq$ $2 \mathrm{~b}$, and this condition must hold with equality at nonzero club consumption levels which are supplied in strictly positive amounts (or more precisely for $b$ in the support of any $\mathbf{x}_{\mathbf{s}}$ ).

Given the nature of the consumption possibility sets, all $\mathrm{x}$ belonging to these sets can be characterized by a pair of real numbers $(\mathrm{a}, \mathrm{b})$ where $\mathrm{a}$ is personal consumption and $\mathrm{b}$ is club consumption. An allocation specifies the distributions of the $(a, b)$ for each type. As we are not keeping track of names, a deterministic allocation will be a set of measures which give the distribution of consumption choices of each type.

An equilibrium consists of a price system and a male and a female distribution of consumption choices which satisfy the following conditions: (i) the total measure of distribution of consumption choices for each sex $s$ is $\lambda_{s}$, (ii) the measure of males and females consuming any nonzero level of club consumption are equal, ${ }^{3}$ (iii) total personal consumption plus two times the total consumption of $b$ over all clubs must be less than or equal to the total endowment, and (iv) the supports of the distributions of consumption choices must consist only of points which are in

\footnotetext{
${ }^{3}$ To be exact, the measure of males and females with club consumption levels which lie in any strictly positive subset of B must be equal.
} 
$\operatorname{argmax}\left\{u(a)+v(b) \mid a+p_{s}(b) \leq e\right\}$, and $(v) p_{f}(b)+p_{m}(b) \leq 2 b$ with equality if club level $b$ is consumed in strictly positive amounts in equilibrium.

\section{Need for Random Contracts}

To see that a deterministic competitive equilibrium is an equilibrium only if people do not have access to a randomization mechanism consider the case where there are more males than females, that is, $\lambda_{m}>\lambda_{f}$. Thus males will be the marginal type, since not all males can be matched. Therefore, a deterministic equilibrium allocation, when one exists, maximizes the utility of females subject to the resource constraint and the constraint that a male's utility in a match is at least as high as it would be if a male consumed his endowment. Let $a_{f}^{*}, a_{m}^{*}$, and $b^{*}$ be the solution to the program

$$
\max \left\{\mathrm{u}\left(\mathrm{a}_{\mathrm{f}}\right)+\mathrm{v}(\mathrm{b})\right\}
$$

subject to

$$
\begin{aligned}
& a_{f}+a_{m}+b \leq \omega_{f}+\omega_{m} \\
& u\left(a_{m}\right)+v(b) \geq u\left(\omega_{m}\right) \\
& a_{f}, a_{m}, b \geq 0
\end{aligned}
$$

This program has a unique solution which implicitly determines the core allocation for this economy. A deterministic competitive equilibrium exists if and only if constraint (1.5) is binding at the optimum. Constraint (1.5) will be binding at the optimum if and only if $\omega_{\mathrm{f}}$ is below some critical value, which, depending on $u$ and $v$, could be plus infinity. If this constraint is binding, the equilibrium distribution of consumption choices for females has measure $\lambda_{f}$ on the point $\left(a_{f}^{*}, b^{*}\right)$ and zero measure elsewhere. The equilibrium distribution of consumption choices for males has measure $\lambda_{\mathrm{f}}$ on the point set $\left\{\left(\mathrm{a}_{\mathrm{m}}^{*}, \mathrm{~b}^{*}\right)\right\}$, measure $\lambda_{\mathrm{m}}-\lambda_{\mathrm{f}}$ on the point set $\left\{\left(\omega_{\mathrm{m}}, 0\right)\right\}$, and zero measure elsewhere. The equilibrium prices of $b^{*}$ are $p_{m}\left(b^{*}\right)=v\left(b^{*}\right) / u^{\prime}\left(a_{m}^{*}\right)$ and $p_{f}\left(b^{*}\right)=2 b^{*}-p_{m}\left(b^{*}\right)$. 
For other $\mathrm{b}$ commodities for which markets clear at zero, we pick the demand reservation prices for males, $\mathrm{p}_{\mathrm{m}}(\mathrm{b})=\mathrm{v}(\mathrm{b}) \mathrm{p}_{\mathrm{m}}\left(\mathrm{b}^{*}\right) / \mathrm{v}\left(\mathrm{b}^{*}\right)$ and set $\mathrm{p}_{\mathrm{f}}(\mathrm{b})=2 \mathrm{~b}-\mathrm{p}_{\mathrm{m}}(\mathrm{b}){ }^{4}$

The allocation implied by the solution to this programming problem is a Pareto optimum in a world without the technology to trade in randomized contracts. If, however, people have access to a randomizing mechanism, this allocations is neither a competitive equilibrium nor a Pareto optimal allocation. We now establish this point.

To establish that this allocation is not a competitive equilibrium, we show that two males can enter into a mutually beneficial gamble. One mutually beneficial gamble is the fair one in which the winner receives $\mathrm{p}_{\mathrm{m}}\left(\mathrm{b}^{*}\right) / 2$ units of the consumption good from the loser. The winner and loser both have personal consumption $\omega_{\mathrm{m}}-\mathrm{p}_{\mathrm{m}}\left(\mathrm{b}^{*}\right)$. The loser has level 0 club consumption while the winner has level $b^{*}$ club consumption. Both these males have expected utility

$$
\text { (1.7) } \mathrm{u}\left(\mathrm{a}_{\mathrm{m}}^{*}+\mathrm{p}_{\mathrm{m}}\left(\mathrm{b}^{*}\right) / 2\right)+\mathrm{v}\left(\mathrm{b}^{*}\right) / 2
$$

which exceeds the utility that they would have realized if they had not entered into the gamble; that is it exceeds $u\left(\omega_{m}\right)=u\left(a_{m}^{*}\right)+v\left(b^{*}\right)$. This last point follows from the strict concavity of the $u$ function and the fact that $\mathrm{p}_{\mathrm{m}}\left(\mathrm{b}^{*}\right)=\mathrm{v}\left(\mathrm{b}^{*}\right) / \mathrm{u}^{\prime}\left(\mathrm{c}_{\mathrm{m}}^{*}\right)$. The existence of a mutually beneficial gamble establishes that the deterministic competitive equilibrium is not an equilibrium if people have access to a randomizing mechanism.

\footnotetext{
${ }^{4} \mathrm{An}$ arbitrary matching of males and females in which each female gets matched with one and only one male, and with the allocation being that a matched pair's consumption is determined by the previous programming problem, while unmatched males simply consume their endowment, is a core allocation. In this core allocation the welfare levels of the male agents will differ if (1.5) does not bind, and hence it cannot be supported as a competitive equilibrium. This core allocation could be supported as a quasi competitive equilibrium (see later discussion) but quasi competitive equilibria need not be competitive equilibria even though there exists a cheaper point in each agent's budget set since the implicit consumption sets are not convex due to the discrete nature of matching. This result stands in contrast to the standard club model with only one fundamental type, where the set of core and equilibrium allocations coincide (see Scotchmer and Wooders 1987).
} 
To show that the deterministic competitive equilibrium is not a Pareto optimum we extend this argument to show that the welfare level of a positive measure of males can be improved relative to the deterministic equilibrium allocation, while leaving the utility of other people unchanged. To do this, simply take an equal positive measure of matched and unmatched males and repeat the above argument. This establishes the existence of a Pareto superior feasible allocation. We now develop a competitive equilibrium model with randomized contracts and show that a competitive equilibrium always exists and that competitive equilibrium allocations are Pareto optimal.

\section{Valuation Equilibria With Lotteries}

Here we will present a formal description of our simple example in which we allow for trade in randomized contracts. We will show that both welfare theorems apply and that a competitive equilibrium always exists.

The form of the example that we will consider is slightly more general in that we will allow for a finite set of possible types of persons indexed by $i=(s, \omega)$ where agents can differ in terms of their sex $s \in\{m, f\}$ and their endowment $\omega>0$. Once again we will use $s$ to denote an individual's own sex and s' the opposite sex.

The commodity space is once again given by $L=R \times M(B) \times M(B)$ with element $x=$ $\left(x_{0}, x_{f}, x_{m}\right)$. The commodity space norm is the sum the absolute value of $x_{o}$ and the total variation norms of $x_{f}$ and $x_{m}$; that is,

$$
\|x\|_{L}=\left|x_{0}\right|+\left\|x_{f}\right\|_{M(B)}+\left\|x_{m}\right\|_{M(B)}
$$

The consumption possibility set of a type i person is

$$
X_{i}=\left\{x \in L_{+}: x_{s^{\prime}}(B)=0, x_{s}(B)=1,\left|x_{0}\right| \leq a_{\max }\right\}
$$


where the number $a_{\max }$ exceeds $\Sigma_{\mathrm{i}} \lambda_{\mathrm{i}} \omega_{\mathrm{i}} / \min \lambda_{\mathrm{i}}$, which is an upper bound for feasible type identical consumptions of the private good. The $\mathrm{U}_{\mathrm{i}}: \rightarrow \mathbf{R}$, the utility function of a type $\mathrm{i}$, is

$$
U_{i}(x)=u\left(x_{0}\right)+\int v(b) x_{s}(d b)
$$

The endowment of a type $i$ is $e^{i}=(\omega, 0,0) \in L_{+}$. The aggregate production possibility set is

(1.11) $Y=\left\{y \in L: y_{f}(Q)=y_{m}(Q)\right.$ for any measurable $Q \subseteq B_{++}$and

$$
\left.\int b y_{f}(d b)+\int b y_{m}(d b)+y_{o} \leq 0\right\} .^{5}
$$

The only major change from our deterministic economy is that we have replaced the restriction in the consumption sets that $x_{s}(\cdot) \in\{0,1\}$ by the restriction $x_{s}(\cdot) \in[0,1]$. The consumption sets are now convex. Here $x_{\delta}(Q)$ has the interpretation of being the probability measure that is placed on outcomes in measurable set $\mathrm{Q} \subset \mathrm{B}$.

We restrict attention to allocations with the property that all people of the same type have the same commodity point. Given that preferences are convex, this is an innocuous restriction that dramatically simplifies notation. ${ }^{6}$ Given this restriction, the resource balance constraint is simply

$$
\sum_{I} \lambda_{i}\left(x^{i}-e^{i}\right)=y
$$

This constraint along with the requirements that $\mathrm{x}^{\mathrm{i}} \in \mathrm{X}_{\mathrm{i}}$ all $\mathrm{i}$ and $\mathrm{y} \in \mathrm{Y}$ define feasible allocations. A price system for our economy is a continuous linear functional $\mathrm{p}: \mathrm{L} \rightarrow \mathbf{R}$ with representation

$$
p \cdot x=x_{o}+\sum_{s} \int p_{s}(b) x_{s}(d b)
$$

${ }^{5}$ By measurable we mean an element of the borel sigma algebra of $B$ which we denote by $B(B)$.

${ }^{6}$ More formally we say competitive equilibria are in the same equivalence class if the $p$ is the same and the type-mean commodity vectors are identical for all types. Within every equivalence class of equilibria there is one type-symmetric equilibrium. 
where the $p_{s}(\cdot)$ functions are integrable. Note $x_{0}$ is the numeraire. A (type-identical) competitive equilibrium for our economy is a price system $\mathrm{p}$ and an allocation $\left[\mathrm{y}^{*},\left\{\mathrm{x}^{\mathrm{i}^{\mathbf{*}}}\right\}\right]$ such that:

(i) $\mathrm{x}^{\mathrm{i} *}$ maximizes $\mathrm{U}_{\mathrm{i}}(\mathrm{x})$ subject to $\mathrm{x} \in \mathrm{X}_{\mathrm{i}}$ and $\mathrm{p} \cdot\left(\mathrm{x}-\mathrm{e}^{\mathrm{i}}\right) \leq 0$,

(ii) $y^{*}$ maximizes $p \cdot y$ subject to $y \in Y$, and

(iii) $\Sigma_{\mathrm{I}} \lambda_{\mathrm{i}}\left(\mathrm{x}^{\mathrm{i}}-\mathrm{e}^{\mathrm{i}}\right)=\mathrm{y}^{*}$.

ProposITION 1. Any competitive equilibrium allocation of this economy is a Pareto optimum.

Proof. The first welfare theorem states that competitive equilibrium allocation are Pareto optimal given local nonsatiation, which holds here because more personal consumption is always preferred to less (see, e.g., Stokey and Lucas 1989, Theorem 15.3).

Proposition 2. Any Pareto optimum allocation with $x_{0}^{i}>0$ for all $i$ can be supported as a competitive equilibrium with transfers.

Proof. If B is finite, the commodity space is finite dimensional and Theorem 15.7 in Stokey and Lucas (1989) implies (type-identical) Pareto optimum can be supported as a (type-homogenous) quasi-competitive equilibrium with transfers. ${ }^{7}$

To establish the second welfare theorem for our economy when the set of club consumptions is not finite, we first establish the second welfare theorem for an economy with a larger production possibility set. This larger aggregate production possibility set has a nonempty interior and has the same sets of (type-identical) Pareto optima and competitive equilibrium as our economy.

${ }^{7} \mathrm{~A}$ quasi-competitive equilibrium is the same as a competitive equilibrium except condition (i) is replaced by $\left(\mathrm{i}^{\prime}\right) \mathrm{U}_{\mathrm{i}}(\mathrm{x}) \geq \mathrm{U}_{\mathrm{i}}\left(\mathrm{x}^{\mathrm{i}^{*}}\right)$ implies $\mathrm{p} \cdot \mathrm{x} \geq \mathrm{p} \cdot \mathrm{x}^{\mathrm{i}^{*}}$. 
Consider the economy with aggregate production possibility set

$$
Y^{\prime}=Y+\left\{y \in L: y_{f}, y_{m} \geq 0, \sigma \int b d y_{f}+\sigma \int b d y_{m}+y_{o} \leq 0\right\} .
$$

This aggregate technology set is the sum of $\mathrm{Y}$ and another technology set which permits the production of the goods $\mathrm{y}_{\mathrm{s}}(\mathrm{b})$ without matching. Let $\sigma$ be sufficiently large that for type-identical Pareto optimal allocations this technology will not be operated. The set $\mathrm{Y}^{\prime}$ has an interior and consequently there is a quasi-competitive equilibrium with a price system in the dual of our commodity space. Given that $\mathrm{y}^{*}$ belongs to $\mathrm{Y}, \mathrm{y}^{*}$ maximizes value over the smaller set $\mathrm{Y}$ given that it maximizes value over the larger set $\mathrm{Y}^{\prime}$. Thus there is a quasi-competitive equilibrium for the prototype economy with a price system in the dual of our commodity space.

Not all points in this dual have the dot product representation that we require for our definition of competitive equilibrium. Given that people discount and truncation is possible (that is Assumptions 15.1-15.7, 15.8', and 15.9' in Stokey and Lucas (1989) are satisfied), a quasicompetitive equilibrium with transfers exists with a dot product representation if one exists with a price system that does not have a dot product representation. ${ }^{8}$

For any Pareto optima with $x_{0}^{i}>0$ for all $i$, and its associated quasi-competitive equilibrium, there will be a cheaper point in the consumption possibility set for every type i. This condition, along with convexity of preferences and consumption sets and continuity of preferences, guarantees that a quasi-competitive equilibrium is a competitive equilibrium.

PROPOSITION 3. A competitive equilibrium always exist for this economy.

\footnotetext{
${ }^{8}$ Before this theorem can be applied the $X_{i}$ must be modified so that truncation is possible. This is done as follows. The point zero is removed from $B$ and the requirement that $x_{s}(B)=1$ is replaced the requirement that $\mathrm{x}_{\mathrm{s}}(\mathrm{B}) \leq 1$. Note $\mathrm{v}(0)=0$.
} 
Proof. If $\mathrm{B}$ is finite, and as a result the commodity space finite dimensional, existence of equilibrium by what McKenzie (1981) calls the classical theorem on existence of competitive equilibrium. For B an interval we follow Bewley (1971) and take the limit of a sequence of equilibria for economies with finite $\mathrm{B}$ sets. For the $\mathrm{n}^{\text {th }}$ economy the set of possible club consumptions is

$$
B_{n}=\left\{0, b_{\max } / n, \ldots,(n-1) b_{\max } / n, b_{\max }\right\}
$$

There will be a subsequence of equilibria for which the allocations converge weak star and the pricing functions $p_{s}$ converge uniformly. ${ }^{9}$ The space of feasible allocations is closed and bounded. This implies that the set of feasible allocations is weak star compact which in turn implies the existence of a weak star convergent subsequence. To establish the existence of a price subsequence which converges uniformly in the $\mathrm{L}_{\infty}$ norm, we show that there exist equilibrium prices for the $n_{t h}$ economy with the property that the slopes of the $p_{s}(b)$ functions are bounded in absolute value uniformly in $b$ and $n$.

The limit of the sequence of the competitive equilibrium for the finite economies is an equilibrium for the limiting economy. For the details of this somewhat tedious proof see the appendix.

\section{Properties of Pareto Optimal and Equilibrium Allocations}

In the previous section we found that competitive equilibria allocations are Pareto optima. Consequently any properties that the Pareto optima have are shared by the competitive equilibria. In this section we establish properties of competitive equilibrium allocations by establishing the properties of the Pareto optima.

\footnotetext{
${ }^{9}$ The pricing functions on the sets $B_{n}$ must be extended to the interval $B$ before considering the limiting arguments.
} 
The prototype economy of the previous section is convex. Consequently, the set of Pareto optima is the closure of the set of solutions to weighted social planner's problems with positive weights. The $\theta$ weighted anonymous social planner problem, where the sum of the $\theta_{\mathrm{i}}$ is one and the $\theta_{\mathrm{i}}>0$, is

$$
\text { (1.13) } \sum_{\mathbf{I}} \theta_{\mathrm{i}} \lambda_{\mathrm{i}} \mathrm{U}_{\mathrm{i}}\left(\mathrm{x}^{\mathrm{i}}\right)
$$

subject to feasibility. These programs are weak star continuous concave programming problems. Given that the constraint set is weak star compact and nonempty, the set of maxima is nonempty and convex.

PROPOSITION 4. For Pareto optima, all people of the same type have the same personal consumption.

Proof. This result follows from the strict concavity of $\mathrm{u}$, the underlying utility function on personal consumption.

A match type is defined by the endowments of the two parties to the match. There is a finite number of possible match types.

PROPOSITION 5. For Pareto optima, all people in a given match type, consume the same level of the club good.

Proof. This result follows immediately from the strict concavity of $\mathrm{v}$, the underlying utility function on club consumption. If this were not the case, having all clubs of the same type have the mean $b$ for the clubs of that type would increase the value of the social planner's objective function without violating feasibility. 
PROPOSITION 6. If $\theta_{\omega s}>\theta_{\omega^{\prime} s}$, then the corresponding Pareto optima satisfy (i) $a_{\omega s}>a_{\omega^{\prime} s}$, (ii) $\mathrm{b}_{\omega \mathrm{s}}>\mathrm{b}_{\omega^{\prime} s}$ with probability one, and (iii) $\mathrm{U}_{\mathrm{i}}\left(\mathrm{x}^{\omega s}\right)>\mathrm{U}_{\mathrm{i}}\left(\mathrm{x}^{\omega^{\prime} s}\right)$.

Proof. If (i) were not true, the objective could be increase by shifting consumption from $\left(\omega^{\prime}, s\right)$ types to $(\omega, s)$ types while maintaining feasibility. If (ii) did not hold, then the objective could be increased by the following switch. Switch a positive measure of type $(\omega, s)$ in a club with club consumption $b_{\omega s}$ with an equal measure type $\left(\omega^{\prime}, s\right)$ who are in clubs with club consumption $b_{\omega^{\prime} s}$. Given (i), (ii), and the fact that the underlying utility functions are strictly increasing, (iii) follows.

We now use these properties of Pareto optima to deduce properties of competitive equilibria. Necessarily, competitive equilibrium utility is increasing in endowment. Therefore, a competitive equilibrium is a solution to some weighted social planner's problem with weights strictly increasing in endowments for each sex. This leads to

PROPOSITION 7. Competitive equilibria are characterized by males (females) with higher endowments being matched with females (males) with weakly higher endowments. For a given type, the personal consumptions of all males are the same as are the personal consumptions of all females. Further, all matches of a given type have the same level of club consumption, and club consumption levels are increasing in the total endowments of the matched pair.

Proof. This follows from the first welfare theorem, Propositions 4-6, and the fact that people with larger endowments must have higher equilibrium utilities.

\section{Computing Lottery Equilibria for the Simple Example}

We now return to our original two type example. As we have already established, a lottery valuation equilibrium is efficient. Therefore, all males have an identical personal consumption level, 
as do all females. We denote these levels as $a_{m}^{*}$ and $a_{f}^{*}$ respectively. Efficiency also requires that all the females be paired and that club good consumption be identical for all matches. Letting $\mathrm{p}_{\mathrm{m}}^{*}$ and $\mathrm{p}_{\mathrm{f}}^{*}$ be the male and female prices of $\mathrm{b}^{*}$ level club consumption, any set of $\left(\mathrm{a}_{\mathrm{f}}, \mathrm{a}_{\mathrm{m}}, \mathrm{b}, \mathrm{p}_{\mathrm{f}}, \mathrm{p}_{\mathrm{m}}\right)$ satisfying the following five equations determines a lottery equilibrium in the case where $\lambda_{m}>\lambda_{f}$ :

(1.13) Male budget constraint: $\mathrm{a}_{\mathrm{m}}+\left(\lambda_{\mathrm{f}} / \lambda_{\mathrm{m}}\right) \mathrm{p}_{\mathrm{m}}=\omega_{\mathrm{m}}$

(1.14) A male marginal condition: $\mathrm{u}^{\prime}\left(\mathrm{a}_{\mathrm{m}}\right) \mathrm{p}_{\mathrm{m}}=\mathrm{v}(\mathrm{b})$

(1.15) Female budget constraint: $a_{\mathrm{f}}+\mathrm{p}_{\mathrm{f}}=\omega_{\mathrm{f}}$

(1.16) Profit maximization requirement: $p_{m}+p_{f}=2 b$

(1.17) Pair efficiency condition: $v^{\prime}(b) / u^{\prime}\left(a_{m}\right)+v^{\prime}(b) / u^{\prime}\left(a_{f}\right)=2$.

This system of equations has a unique solution whenever the measures of males and females are not equal. To see this consider the following: We can use (1.13) and (1.14) to derive a functional relationship $a_{m}(b)$ which must hold for any solution to this system of equations. The function $\mathrm{a}_{\mathrm{m}}(\mathrm{b})$ has a negative slope. Equations (1.14)-(1.15) can be solved for $\mathrm{a}_{\mathrm{f}}$ as a function of $b$ and $a_{m}$. Using the $a_{m}(b)$ function and this function, yields $a_{f}(b)$ which has a negative slope. Using these functions to substitute for $a_{f}$ and $a_{m}$ in (1.17) yields a function $h(b)=2$. The facts that the $a_{f}(b)$ and $a_{m}(b)$ have negative slope and function $v(b)$ is strictly concave implies that the continuous function $h(b)$ has negative slope. Consequently there is at most one solution to this system of equations.

Let $\pi$ denote the fraction of females and consider the case where $\omega_{\mathrm{f}}=\omega_{\mathrm{m}}=1$. The symmetry of the model implies that equilibrium utilities satisfy $U_{m}^{*}(\pi)=U_{f}^{*}(1-\pi)$, and that the club good consumption level of matched pairs along with the sex specific prices, are symmetric around 1/2. We plot the equilibrium utility function of males in Figure 1 along with the utility level in the deterministic economy. Note the equilibrium utility level in the lottery does not exhibit the knife 
edge property of the deterministic economy. Instead, a sex benefits at the margin if their relative number is smaller. Secondarily, the band of indeterminacy at $1 / 2$ is smaller in the lottery economy than in the deterministic economy because in the lottery economy some of the surplus from matching begins to accrue to the more numerous sex prior to the equalization of relative numbers. This occurs because in the lottery economy people can reduce their probability of being matched and this extra margin reduces the "market power" of the scarce sex relative to the deterministic economy where matching is all or nothing. As a result, in the lottery economy the females do relatively worse as $\pi$ approaches $1 / 2$ from below, since in equilibrium they are not able to force the males down to their no trade welfare levels.

In the lottery economy, and unlike the deterministic economy except at $\pi=1 / 2$, the equilibrium allocation varies with $\pi$. The level of club good consumption declines monotonically as $\pi$ approaches $1 / 2$ from above or below. This is because the implicit transfer from unmatched agents to matched agents is going to zero. The level of male personal consumption is 1 at $\pi=0$, somewhat above the female level. Male personal consumption monotonically falls as $\pi$ rises to $1 / 2$, while the female level rises substantially above the male level prior to $\pi$ reaching $1 / 2$.

In the limiting case, as $\pi \rightarrow 1$, the probability of a female getting matched is going to zero. Note that since $v(\cdot)$ is bounded, this implies that $\pi p_{f} \rightarrow 0$, otherwise the females would be forced below their no-trade welfare level in the limit. Since in equilibrium the number of probability units of being matched that each female is purchasing must also go to zero, the female's marginal price of being matched is converging to $v(b) / u^{\prime}(1)$. The equilibrium welfare level of the males in the limit is therefore the solution to the following maximization problem:

$$
\mathrm{U}_{\mathrm{m}}^{*}(1)=\max \left\{\mathrm{u}\left(\mathrm{a}_{\mathrm{m}}\right)+\mathrm{v}(\mathrm{b})\right\}
$$


subject to $a_{m}+2 b \leq 1+v(b) / u^{\prime}(1)$. The females welfare level is just their no-trade welfare level, $u(1)$.

We can also use this comparison of the different equilibrium outcomes in the two economies to clarify the distinction between equilibria in one economy and Pareto optima in the other. First, only in the case where $\pi=1 / 2$ can an equilibria in the deterministic economy be Pareto optimal in the lottery economy, since only then are the personal consumption levels equalized for all members of a particular sex. Second, while the ex-post lottery equilibrium outcomes are Pareto optimal in the deterministic economy, only in the case where $\pi=1 / 2$ are they equilibria.

\section{Alternative Decentralizations}

Consider our simple two type example when there are twice as many males as females. The equilibrium allocation for our lottery economy could be supported by different decentralizations. One way is for two male agents to get together, pooled their resources, and entered into an arrangement with a female agent in which they agreed to contribute $\mathrm{p}_{\mathrm{m}}\left(\mathrm{b}^{*}\right)$, while setting aside a personal consumption level of $a_{m}^{*}=\omega_{m}-p_{m}\left(b^{*}\right) / 2$ for each of them. They then flip a coin to see which one of them gets to be matched with the female, and thereby consumes the club good along with his personal consumption good. In this scenario the males are gambling over final allocations directly. An alternatively way is that they first entered into the following wealth gamble: they flip a coin, and the loser pays the winner $\mathrm{p}_{\mathrm{m}}\left(\mathrm{b}^{*}\right) / 2$; after which they face a standard deterministic market in final consumption which here includes the club good. The first scenario is essentially the decentralization that we have consider thus far, though the second may seem more appealing on positive grounds. However, this discussion suggests that the set of equilibrium allocations are equivalent under either decentralization. Later we show for the general class of club economies that this is in fact the case. 


\section{A More General Class of Economies With Clubs}

The method of decentralization that we have considered is applicable to a richer class of environments than the simple example that we have thus far considered might suggest. Here we indicate how one can accommodate a much wider range of matching models, with a greater variety of types and a more extensive set of joint activities being undertaken. We can also allow for multiple club membership; for example an individual can be a member of both a household and a production club.

Set of People: There are a finite number of types of people indexed by $\mathrm{i} \in \mathrm{I}$. The measure of type $\mathrm{i}$ is $\lambda_{\mathbf{i}}>0$. We will refer to a distinction between two types of people as being basic if some club technology does not treat them as perfect substitutes. In the previous section the sex distinction is basic. Type i's basic type is $s_{i} \in S$, where $S$ is a finite set.

Commodities: The set of possible personal consumptions belong to A, a compact subset of some Euclidean space. There are a finite set of categories of clubs indexed by $j=1, \ldots, \mathrm{J}$. Each person must be a member of one and only one club in each category. Forcing membership is not a restriction since one can allow for a single member club which does nothing in each category. We denote the set of possible club consumption vectors in category $j$ by $B_{j}$, which like $A$ is a compact subset of a Euclidean space. We define $\mathrm{C} \equiv \mathrm{A} \times \mathrm{B}_{1} \times \ldots \times \mathrm{B}_{\mathrm{J}}$. The commodity space is $\mathrm{L} \equiv$ $\mathrm{M}(\mathrm{C})^{\# \mathrm{~S}}$, where $\mathrm{M}(\mathrm{C})$ denotes the set of signed measures on the Borel sigma algebra of $\mathrm{C}$ and \#S denotes the cardinality of S.

Preferences and Endowments: A person of type i has preferences over probability measures on the Borel sigma algebra of $C_{i}$, a closed measurable subset of $C$, ordered by the expected value of the continuous function $u_{i}(c)$ defined on $C_{i}$. Type i's consumption possibility set is

$$
X_{i}=\left\{x \in L_{+}: x_{s}\left(C_{i}\right)=x_{s}(C)=1, x_{s^{\prime}}=0 \text { for } s^{\prime} \not s\right\}
$$


The utility functions $U_{\mathrm{i}}: \mathrm{X}_{\mathrm{i}} \rightarrow \mathbf{R}$ are

$$
\mathrm{U}_{\mathrm{i}}(\mathrm{x})=\int \mathrm{u}_{\mathrm{i}} \mathrm{dx}_{\mathrm{s}}
$$

(Here and subsequently the subscript $i$ on $s$ will be implicit.) The endowment point of a type $i$ is a point $\mathrm{e}^{\mathrm{i}} \in \mathrm{L}$ with $\mathrm{e}_{\mathrm{s}^{\prime}}^{\mathrm{i}}=0$ for $\mathrm{s}^{\prime} \neq \mathrm{s}$ and with $\mathrm{e}_{\mathrm{s}}^{\mathrm{i}}$ being the measure that assigns measure 1 to sets containing $\omega_{\mathrm{i}} \in \mathrm{C}$, and 0 to all other sets.

Club Technologies: A club type of category $\mathrm{j}=1, \ldots, \mathrm{J}$ is defined by its vector of exchangeable commodities $a$, the vector of club goods $b_{j}$, and its membership $n$. It's membership vector $\mathrm{n}$ specifies the integer number of each basic type $\mathrm{s}$ in the club. The set of possible memberships is the finite set $N$. Thus, a club type in category $j$ is denoted $t_{j} \in A \times B_{j} \times N$. The set of possible category $\mathrm{j}$ club types is $\mathrm{T}_{\mathrm{j}} \subseteq \mathrm{A} \times \mathrm{B}_{\mathrm{j}} \times \mathrm{N}$, for $\mathrm{j}=1, \ldots, \mathrm{J}$.

Aggregate Production Possibility Set: In order to determine whether or not a point y $\in \mathrm{L}$ is in the aggregate production set $\mathrm{Y}$, there must be a distribution of types of clubs in each category which is consistent both with $y$ and $T_{j}$ for all $j=1, \ldots, J$. Since any number of clubs of a given type can be operated and the output of any club has measure zero, the aggregate production technology is a cone. The specification of $\mathrm{Y}$ requires that we first specify the set of possible measure of types that are operated, given the club technologies. To do this we define $\Delta_{j}$ to be the set of measures on $M_{+}\left(A \times B_{j} \times N\right)$ with support in $T_{j}$. The measure $\delta_{j} \in \Delta_{j}$ specifies the number of clubs of category $j$ belonging to the Borel measurable subsets of $T_{j}$.

The aggregate production possibility set is

$$
\begin{aligned}
& Y=\left\{y \in L: \exists \text { a set of measures }\left\{\delta_{j}\right\} \text { with } \delta_{j} \in \Delta_{j}\right. \text { for which } \\
& \text { (i) } \sum_{J} \int a \delta_{j}\left(d t_{j}\right)=\sum_{s} \int a y_{s}(d c) \\
& \text { (ii) } \left.\int n_{s} \delta_{j}\left(d t_{j} \mid b_{j} \in Q\right)=\int y_{s}\left(d c \mid b_{j} \in Q\right) \text { all } j, s \text {, and measurable } Q\right\} .
\end{aligned}
$$


Constraint (i) is that the net supplies of commodities a summed over all clubs is equal to aggregate net supply of a. Constraints (ii) are that the measure of people of type $s$ receiving club consumption $b_{j} \in Q$ in the output measure be consistent with the distribution of clubs in category $j$.

Remark: Given that both the consumption possibility sets and the preference ordering are convex, then given any equilibrium there is an equivalent type identical equilibrium. The equivalence is in terms of the price system $p$, the aggregate supply $y$, the expected utilities, and for each type the distribution of $c$ over people of that type.

Price System and Competitive Equilibrium: A price system for our economy is a linear functional p: $\mathrm{L} \rightarrow \mathbf{R}$ with representation

$$
p \cdot x=\sum_{s} \int p_{s}(c) x_{s}(d c)
$$

where the $\mathrm{p}_{\mathbf{s}}: \mathrm{A} \times \mathrm{B} \rightarrow \mathbf{R}$ are measurable..

A type identical competitive equilibrium for our economy is a price system $\mathrm{p}$ and an allocation $\left[\left\{\mathrm{x}^{\mathrm{i}^{*}}\right\}, \mathrm{y}^{*}\right]$ such that:

(i) $\mathrm{x}^{\mathrm{i}^{*}}$ maximizes $\mathrm{U}_{\mathrm{i}}(\mathrm{x})$ subject to $\mathrm{x} \in \mathrm{X}_{\mathrm{i}}$ and $\mathrm{p} \cdot \mathrm{x} \leq \mathrm{p} \cdot \mathrm{e}^{\mathrm{i}}$,

(ii) $y^{*}$ maximizes $\mathrm{p} \cdot \mathrm{y}$ subject to $\mathrm{y} \in \mathrm{Y}$, and

(iii) $\Sigma_{\mathrm{i}} \lambda_{\mathrm{i}}\left(\mathrm{x}^{\mathrm{i}^{*}}-\mathrm{e}^{\mathrm{i}}\right)=\mathrm{y}^{*}$.

\section{The Welfare Theorems and Existence}

As in the simple economy, the first welfare theorem follows from local nonsatiation (see Theorem 15.3 in Stokey and Lucas 1989). Given the convexity of consumption sets, continuity of preferences and our restriction to type identical allocations, if there exists a point in each type's consumption set which is strictly preferred to all points which are that type's consumption for some feasible allocation, then local nonsatiation will hold. 
Just as in our two sex matching model establishing the second welfare theorem is somewhat more complicated. If $\mathrm{L}$ were finite dimensional and/or $\mathrm{Y}$ had an interior point, Theorem 15.4 in Stokey and Lucas (1989) could be applied to conclude that all Pareto optimum can be supported as a quasi-competitive equilibrium with transfers. If this is not the case, then one may be able to proceed, as in the two sex matching model, to establish the second welfare theorem for an economy which has a larger production possibility set that has an interior, but which has the same set of Pareto optima and competitive equilibrium as our economy.

The second welfare theorem guarantees the existence of a competitive equilibrium in which the price system is a continuous linear functional on the commodity space. This does not imply that this price system has a dot product representation when the commodity space is infinite dimensional. To establish the existence of a competitive equilibrium with transfers and with a price system that has a dot product representation, we verify that assumptions $15.8^{\prime}$ and $15.9^{\prime}$ in Stokey and Lucas (1989, p. 468) hold and apply their Theorem 15.9. Assumption 15.8 ' requires that if $x \in X_{i}$, the modification of $x$ obtained by setting the $x_{s}$ equal to zero on some measurable subset of $B$ is also in $\mathrm{X}_{\mathrm{i}}$. If $\omega_{\mathrm{i}} \in \mathrm{C}_{\mathrm{i}}$, the $\mathrm{x}\left(\left\{\omega_{\mathrm{i}}\right\}\right)$ correspond to the zero point. More generally (see Prescott and RiosRull 1992) for the case $\mathrm{W}_{\mathrm{i}} \notin \mathrm{C}_{\mathrm{i}}$. Assumption $15.9^{\prime}$ is essentially that preferences are weak star continuous which is the case given expected utility maximization and the fact that the function $p$ is bounded and continuous.

If $C$ is finite, the existence proof discussed in McKenzie (1981) will generally apply. Note that (i) the consumption sets are closed and convex, (ii) the preference ordering is continuous and quasi concave, and (iii) the aggregate production set is a closed convex cone. The additional assumptions that need to be satisfied are:

(iv) $\mathrm{X}_{\mathrm{i}}+\left\{-\mathrm{e}^{\mathrm{i}}\right\} \cap \mathrm{Y}$ is not empty,

(v) $\mathrm{Y} \cap \mathrm{R}_{+}=\{0\}$, 
(vi) There is a common point in the relative interiors of $Y$ and $X=\Sigma_{I} \lambda_{i}\left(X_{i}+\left\{-e^{i}\right\}\right)$, and

(vii) For any two nonempty, disjoint partitions of $I, I^{\prime}$, and $I^{\prime \prime}$, and $x^{\prime}=y-x^{\prime \prime}$, where $x^{\prime} \in$ $\Sigma_{\mathrm{I}} \lambda_{\mathrm{i}}\left(\mathrm{X}_{\mathrm{i}}+\left\{-\mathrm{e}^{\mathrm{i}}\right\}\right), \mathrm{x}^{n} \in \Sigma_{\mathrm{I}^{n}} \lambda_{\mathrm{i}}\left(\mathrm{X}_{\mathrm{i}}+\left\{-\mathrm{e}^{\mathrm{i}}\right\}\right)$ and $\mathrm{y} \in \mathrm{Y}$, there exists a $\mathrm{w} \in \Sigma_{\mathrm{I}^{n} \lambda_{\mathrm{i}}}\left(\mathrm{X}_{\mathrm{i}}+\right.$ $\left.\left\{-e^{i}\right\}\right)$, such that $x^{\prime}+x^{\prime \prime}+w \in Y$, and $x^{\prime}+w$ can be decomposed into an allocation for $I^{\prime}$ which is weakly preferred by all members of $I^{\prime}$ and strictly by at least one.

There are obviously many ways to satisfy (iv), for example our simple two type matching model autarky is feasible. If we assume that the projection of $T_{j}$ on $A \times B_{j}$ only intersects the positive orthant at $\{0\}$ for all $j$, then the finite dimensional version of our general model satisfies (v). There are many ways to satisfy (vi); the requirement that there is a feasible set of net trades and associated output which lie in the interior of the smallest hyperplane containing $\mathrm{Y}$ and the smallest hyperplane containing the sum of the sets of net trades consistent with both individual consumption sets and endowments. There are also many ways to satisfy (vii) which ensures that all agents have positive income; for example, in the prototype economy there was a good which was desired by all and with which every type was positively endowed.

If $\mathrm{C}$ is not finite, the commodity space is infinite dimensional and establishing the existence of a competitive equilibrium is more difficult. A standard method of proof is show the limit of a sequence of equilibria for finite dimensional economies exists and is an equilibrium for the infinite dimensional limit economy. An outline of this approach as applied to our class of economies is as follows. Restrict the aggregate production possibility set to elements whose support belong to finite set $C_{n} \subset C$ where all points in $C$ lie in a $1 / n$-neighborhood of at least one some point in $C_{n}$. For economy $\left[\left\{X_{i}, u_{i}, e^{i}\right\}, Y_{n}\right]$ the commodity space $L_{n}=M\left(C_{n}\right)^{\text {HS }}$ in finite dimensional. Given competitive equilibrium $\left[\left\{x_{n}^{i}\right\}, y_{n}, P_{n}\right] \mid$ for the $n^{\text {th }}$ economy, the problem is to find a convergent subsequence with the property that the limit is an equilibrium for our economy with $Y_{n}$ unrestricted. 
Given that the underlying $u_{i}$ are continuous, the $U_{i}$ are weak star continuous. Given that the set of type identical allocations are close and bounded, there must be a weak star convergent subsequence of the allocation $\left[\left\{x_{n}^{i}\right\}, y_{n}\right]$ with $\lim y_{n} \in Y$ and with $\lim U_{i}\left(x_{n}^{i}\right)=U_{i}\left(\lim x_{n}^{i}\right)$ for each type i.

The key part of the proof is to find a uniformly convergent subsequence of the $p_{n}$. This insures that $\lim x_{n}^{i}$ is maximal given price system $p=\lim p_{n}$ where $n$ now indexes elements of the sub subsequence for which allocations converge weak star and prices uniformly. For our economy, if the $u_{i}(c)$ have uniformly bounded slopes, a sequence of competitive equilibria exists with the desired property. First we normalize prices so that the $\sup \left|p_{n s}(c)\right|=1$. Next we let $r_{n s}(c)$ be the maximal reservation price over all $i \in I(s)$. Note the $r_{n s}$ functions are defined on all of $U_{I(s)} C_{i}$. Note also that $\left[\left\{x_{n}^{i}\right\}, y_{n}, r_{n}\right]$ is a competitive equilibrium for economy with commodity space $L=$ $M(C)^{\# S}$ and aggregate technology set $Y_{n}$. The functions $r_{n s}(c)$ will have uniformly bounded slopes given the underlying utility function $u_{i}(c)$ have uniformly bounded slope. This completes the outline of the extension to economies with $\mathrm{C}$ being a compact metric space.

\section{Equivalence of Core and Equilibrium Allocations}

In this section we show that the standard arguments with regard to the equivalence of the set of core and equilibrium allocations hold with a lottery commodity space. That this was not the case in our prototype economy with a deterministic commodity space was pointed out in footnote 4 . In order to specify a core allocation we will need to allow for allocations in which agents of a given type not only do not receive the same commodity point, but may in fact enjoy different welfare levels. We then show that any core allocation must satisfy equal welfare among people of the same type. Next we show that any equilibrium allocation is in the core. Finally we show that given a 
core allocation there exists a price system which will support it as a quasi competitive equilibrium, and discuss the conditions under which a quasi competitive equilibrium is a competitive equilibrium.

A general definition of an allocation is a set of measures $z=\left\{z_{i}\right\}$, where $z_{i}$ is a map from the Borel sigma algebra of $\mathrm{L}$ to $\mathbf{R}_{+}$such that $\mathrm{z}_{\mathrm{i}}\left(\mathrm{X}_{\mathrm{i}}\right)=\lambda_{\mathrm{i}}$ all $\mathrm{i}$. A suballocation is similar to an allocation except that we weaken the membership restriction to be $\lambda_{i}(z) \equiv z_{i}\left(X_{i}\right) \leq \lambda_{i}$ for all $i$. An (sub) allocation $z$ is feasible if: (i) the support of $z_{i}$ is a subset of $X_{i}$ for all $i$, and (ii) $\Sigma_{\mathrm{I}} \int\left(\mathrm{x}-\mathrm{z}_{\mathrm{i}}\right) \mathrm{z}_{\mathrm{i}}(\mathrm{dx}) \equiv \mathrm{y}(\mathrm{z}) \in \mathrm{Y}$.

We say (sub) allocation $\tilde{\mathbf{z}}$ Pareto dominates (sub) allocation $\mathbf{z}$ if

(i) $\quad \lambda(\tilde{\mathbf{z}})=\lambda(\hat{z})$ and

(ii) $\quad \tilde{\mathbf{z}}_{\mathrm{i}}\left(\left\{\mathrm{x} \in \mathrm{X}_{\mathrm{i}}: \mathrm{U}_{\mathrm{i}}(\mathrm{x}) \geq \mathrm{u}\right\}\right) \geq \hat{\mathrm{z}}_{\mathrm{i}}\left(\left\{\mathrm{x} \in \mathrm{X}_{\mathrm{i}}: \mathrm{U}_{\mathrm{i}}(\mathrm{x}) \geq \mathrm{u}\right\}\right)$

all $i \in I, u \in \mathbf{R}$ with strict inequality for some (i,u).

Feasible suballocation $\tilde{z}$ blocks feasible allocation $\mathrm{z}$ if there suballocation $\hat{z} \leq \mathrm{z}$ with the properties (i) $\lambda(\hat{z})=\lambda(\bar{z})$ and (ii) $\tilde{z}$ Pareto dominate $\hat{z}$.

Note $z$ is the distribution of consumptions under allocation $\mathrm{z}$ of the blocking coalition while $\tilde{\mathbf{z}}$ is their distribution under the blocking allocation. An allocation $\mathbf{z}$ is a core allocation if no suballocation blocks it.

PROPOSITION 8. If $z$ is a core allocation, all people of the same type receive the same welfare level.

Proof. If utilities were not equal for almost all of each type, a feasible allocation could be blocked as follows. Select the measures $\epsilon \lambda_{i}$, where $0<\epsilon<1$, of people of type $i$ who receive the lowest utility levels under $z$. For $\epsilon$ sufficiently small all members of this coalition $z$ receive utility levels weakly less than their type average level for $\mathrm{z}$. Further for this coalition a positive measure of some type receive utility levels strictly below the average for $\mathbf{z}$. A suballocation which is feasible relative to this coalition is for all of type $i$ to receive the average $x^{i}$ for the $z$ allocation. This follows given 
feasibility of $\mathrm{z}$ and the fact that $\mathrm{Y}$ is a cone. This feasible suballocation would block $\mathrm{z}$. This establishes the proposition.

A competitive equilibrium which is consistent with our general definition of an allocation is a triplet $[\mathrm{z}, \mathrm{y}, \mathrm{p}]$ such that: (i) the support of $\mathrm{z}^{\mathrm{i}} \subseteq \operatorname{argmax}\left\{\mathrm{U}_{\mathrm{i}}(\mathrm{x}): \mathrm{x} \in \mathrm{X}_{\mathrm{i}}\right.$ and $\left.\mathrm{p} \cdot \mathrm{x} \leq \mathrm{p} \cdot \mathrm{e}^{\mathrm{i}}\right\}$ and (ii) $\mathrm{y} \in \operatorname{argmax}_{\mathbf{Y}} \mathrm{p} \cdot \mathrm{y}$, and (iii) $\sum_{\mathrm{I}} \int\left(\mathrm{x}-\mathrm{e}^{\mathrm{i}}\right) \mathrm{z}^{\mathrm{i}}(\mathrm{dx})=\mathrm{y}$. Given a type identical competitive equilibrium $\left[\left\{x_{i}\right\}, y, p\right]$, we can construct its associated general competitive equilibrium $[z, y, p]$ in the obvious manner: have $z^{i}$ put weight $\lambda^{i}$ on sets containing $x^{i}$ and 0 otherwise. For a quasi competitive equilibrium condition (i) is replaced by the following:

(i') If $x^{\prime}$ is in the support of $z^{i}$, then for any $x \in X_{i}, U_{i}(x) \geq U_{i}\left(x^{\prime}\right)$ implies $p \cdot x \geq p \cdot x^{\prime}$.

PROPOSITION 9. If $[z, y, p]$ is a competitive equilibrium, then its allocation $z$ is a core allocation.

Proof. We note first that for a competitive equilibrium all people of the same type have the same utility level. If suballocation $\tilde{\mathbf{z}}$ blocked $\mathrm{z}$, for all people in $\tilde{\mathbf{z}}$

$$
p \cdot \tilde{\mathbf{x}}^{\mathrm{i}} \geq \mathrm{p} \cdot \mathrm{x}^{\mathrm{i}}
$$

with strict inequality for those in $\tilde{z}$ whose utility is strictly higher than under the $z$ allocation. This implies that

$$
p \cdot y(\tilde{z})=\sum_{I} \int p \cdot\left(x-e^{i}\right) \tilde{z}^{i}(d x)>0
$$

Feasibility of $\tilde{\mathbf{z}}$ requires $\mathrm{y}(\tilde{\mathbf{z}}) \in \mathrm{Y}$. But, given $\mathrm{Y}$ is a cone, the maximum equilibrium profits must be zero. This contradiction establishes the proposition.

In order to show the existence of a price system which supports a core allocation as a quasi competitive equilibrium we will need to apply the Hahn-Banach theorem. However, just as with the second welfare theorem, the potential emptiness of the production set when the commodity space is 
infinite dimensional precludes this theorem's direct application. There are two obvious resolutions to this problem: (i) assume that $\mathrm{C}$ is finite and hence $\mathrm{L}$ is finite dimensional, or (ii) construct an alternative production set $\mathrm{Y}^{\prime}$ which includes $\mathrm{Y}$ and for which the set of Pareto optimal allocations is the same regardless of the distribution of the population (the $\lambda$ 's). The condition in (ii) is stronger than with the second welfare theorem since we need to ensure that given any blocking sub allocation which is feasible for production set $\mathrm{Y}^{\prime}$, there is at least as good a suballocation which is feasible for $\mathrm{Y}$, and hence the expansion in the set of possible blocking suballocations under $\mathrm{Y}^{\prime}$ has not shrunk the core. We pursue approach (i) below. Approach (ii) can be applied in our prototype economy.

PROPOSITION 10. If $C$ is finite, then for any core allocation $z$, there exist a $p$ and $y$ such that $[z, p, y]$ is a quasi competitive equilibrium.

Proof. The proof is by construction. Since $\mathrm{z}$ is a feasible allocation, with $\mathrm{y}=\mathrm{y}(\mathrm{z})$ condition (iii) is satisfied. Now, we need only find a supporting price system wherein conditions (i') and (ii) are satisfied. The proof is in two parts, first we establish the existence of a supporting hyperplane which satisfies certain conditions, from which we derive a price system. Then we establish that this price system along with our allocation and $y(z)$ is a quasi competitive equilibrium.

First, from Proposition 6, for any core allocation there is a unique utility level associated with each type which we denote by $\mu_{\mathrm{i}}$. This utility level implies a preferred set of net consumptions for each type $\mathrm{X}_{\mathrm{i}}^{+}=\left\{\mathrm{x} \in \mathrm{X}_{\mathrm{i}}: \mathrm{U}_{\mathrm{i}}\left(\mathrm{x}+\mathrm{e}^{\mathrm{i}}\right)>\mu_{\mathrm{i}}\right\}$. Let $\mathrm{X}^{+}$denote the convex hull of $U_{\mathrm{i}} \mathrm{X}_{\mathrm{i}}^{+}$. Now, we want to establish that $\mathrm{X}^{+} \cap \mathrm{Y}$ is empty. Assume otherwise; that is that there exists a set of weights $\left\{\theta_{\mathrm{i}}\right\}$ and points $\left\{\mathrm{x}^{\mathrm{i}} \in \mathrm{X}_{\mathrm{i}}^{+}\right\}$such that $\Sigma_{\mathrm{i}} \theta_{\mathrm{i}} \mathrm{x}^{\mathrm{i}} \in \mathrm{Y}$. But then we could construct a blocking suballocation where the relative measures of each type corresponded to those implied by these weights, and where each type $i$ in the blocking coalition receives $x^{i}$. Hence, by contradiction the intersection is empty. Given that $\mathrm{C}$ is finite and hence $\mathrm{L}$ is finite dimensional, the Hahn-Banach 
thereon guarantees that there exists a separating hyperplane, which since $L$ is finite dimensional, we can represent as a point $p$ in $L$.

Now, in order to establish that $z, p$, and $y(z)$ is a quasi competitive equilibrium we need only show that conditions (i') and (ii) are satisfied. To show that (ii) is satisfied, note that from the continuity of preferences $\mathrm{y}(\mathrm{z})$ is in the closure of the set $\Sigma_{\mathrm{i}} \mathrm{X}_{\mathrm{i}}^{+}$. Since $\Sigma_{\mathrm{i}} \mathrm{X}_{+}^{\mathrm{i}}$ is a subset of the convex hull of $U_{\mathrm{i}} \mathrm{X}_{+}^{\mathrm{i}}$ and our price system is continuous, this implies that $\mathrm{p} \cdot \mathrm{y}(\mathrm{z}) \geq \mathrm{p} \cdot \mathrm{y}$ for all $\mathrm{y} \in \mathrm{Y}$. By an analogous argument, where we make use of the fact that the continuity of preferences implies that the support of $z^{i}$ is in the closure of $X_{i}^{+}$, we can establish ( $\left.i^{\prime}\right)$.

Just as in the second welfare theorem, the existence of a cheaper point than the support of $z^{i}$ in i's budget set for each $i$, along with the convexity of consumption sets implies that a quasi competitive equilibrium is a competitive equilibrium. In the case of deterministic competitive equilibria, consumption sets are not convex, and this argument does not hold. This is why this equivalence failed to hold in our simple two type example discussed earlier, even though all agents had positive endowments of the numeraire good.

As a final point, note that for any equal welfare Pareto optimal allocation, which includes any core or general competitive equilibrium allocation, there is an equivalent type-identical allocation. By equivalent, we mean that the associated utilities are the same, and further the implied distribution over the underlying consumption space $\mathrm{C}$ by type is the same. To construct the equivalent typeidentical allocation of an equal welfare allocation $z$, simply put mass $z^{i}\left(X_{i}\right)$ on sets containing the point $x^{i}=\int x z^{i}(d x)$ for each $i \in I$. To see that this new allocation is equivalent to our original allocation, note first that since preferences are convex, welfare levels cannot be lower. They also cannot be higher since the initial allocation was a Pareto optimum and the new allocation is certainly feasible. Finally, note that by construction the distribution over the underlying commodity space by 
type is unchanged. These fairly obvious insight is what motivated our restricting ourselves to type homogeneous allocations in the previous sections of the paper.

\section{Equivalence of Lottery and Value-Gamble Equilibria}

A gambling decentralization is a two-stage process with gambles over value transfers in the first stage and a deterministic competitive equilibrium in the second. We will show that the set of equilibria for the two-stage gambling decentralization is equivalent to the set of lottery equilibria.

In the first stage of our gambling economy agents can enter into actuarially fair gambles over value transfers. The second stage of our gambling economy is just deterministic version of our general lottery economy. The only change in switching to a deterministic economy from a lottery economy is that condition (i) in the definition of a competitive equilibrium becomes

$$
\text { Support of } \mathrm{x}^{\mathrm{i}^{*}} \subseteq\left\{c \in \operatorname{argmax}\left\{\mathrm{u}^{\mathrm{i}}(\mathrm{c}): \mathrm{p}_{\mathrm{s}}(\mathrm{c}) \leq \mathrm{p} \cdot \mathrm{e}^{\mathrm{i}}\right\} .\right.
$$

Note in our definition of a deterministic competitive equilibrium we are implicitly allowing agents of the same type to make different choices of $c$ only if they are indifferent over these choices ex post.

The set of permissible value transfers in the first stage is denoted by $W=\left[w_{\min }, w_{\max }\right]$. An allocation is a set $\mathrm{g}=\left\{\mathrm{g}_{\mathrm{i}}\right\}$ where $\mathrm{g}_{\mathrm{i}} \in \mathrm{M}_{+}(\mathrm{W} \times \mathrm{C})$ and $\mathrm{g}^{\mathrm{i}}(\mathrm{W} \times \mathrm{C})=1$ for all $\mathrm{i}$. The preferences of agent $\mathrm{i}$ over $\mathrm{M}_{+}(\mathrm{W} \times \mathrm{C})$ are given by

$$
\mathrm{U}_{\mathrm{i}}(\mathrm{g})=\int \mathrm{u}_{\mathrm{i}}(\mathrm{c}) \mathrm{g}_{\mathrm{i}}(\mathrm{dw} \times \mathrm{dc})
$$

A gambling equilibrium is an allocation $\mathrm{g}$, an output $\mathrm{y}$, and a price system $\mathrm{p}$ in the dual of $\mathrm{M}(\mathrm{C})^{\text {HS }}$ such that 
(i) $\quad g_{i}$ maximizes $U_{i}(g)$ subject to (1) $\int w g_{i}(d w \times d c)=0$ and

(2) the support of $g_{i}^{*} \subseteq\left\{(w, c) \in W \times C: c \in \operatorname{argmax}\left\{u^{i}(c): p_{s}(c) \leq p \cdot e^{i}+w\right\}\right\}$,

(ii) $y^{*}$ maximizes $\mathrm{p} \cdot \mathrm{y}$ subject to $\mathrm{y} \in \mathrm{Y}$, and

(iii) $\Sigma_{\mathrm{I}(\mathrm{s})} \lambda_{\mathrm{i}} \int \mathrm{g}_{\mathrm{i}}^{*}(\mathrm{dw}, \cdot)-\mathrm{e}^{\mathrm{i}}(\cdot)=\mathrm{y}_{\mathrm{s}}^{*}(\cdot)$, where $\mathrm{I}(\mathrm{s}) \equiv\left\{\mathrm{i} \in \mathrm{I}: \mathrm{s}^{\mathrm{i}}=\mathrm{s}\right\}$.

We will refer to an equilibrium in our lottery economy being equivalent to an equilibrium in the gambling economy if the price functions and output measure and ex ante welfare levels by type are the same, and if the marginal distributions over consumption by type are equal; that is $\mathrm{g}^{\mathrm{i}}(\mathrm{dc})=$ $x_{8}^{i}$ for all $i$.

PROPOSITION 11 . The set of equilibria in the lottery economy are equivalent to the set of equilibria in the gambling economy.

Proof. Let $\left[\mathrm{y}^{\ell}, \mathrm{p}^{\ell},\left\{\mathrm{x}^{\mathrm{i}}\right\}\right]$ denote an equilibrium in the lottery economy and let $\left[\mathrm{y}^{\mathrm{g}}, \mathrm{p}^{\mathbb{g}},\left\{\mathrm{g}_{\mathrm{i}}\right\}\right]$ denote an equilibrium in the gambling economy. Since the production sets are the same in the two economies, the set of profit maximizing production measures are also the same in the two economies if the price functions are. Thus the equivalence of the production side follows trivially. Hence we need only show that given an equilibrium consumption allocation in each economy, we can construct an equivalent feasible allocation in the other economy which is optimal for each of agents, given that $\mathrm{p}^{\ell}=\mathrm{p}^{\mathrm{g}}$. To do this we will show that given an equilibrium allocation in one economy we will show that we can construct an allocation in the other economy which yields equal ex ante utility by type, which is feasible for each type given that $\mathrm{p}^{\ell}=\mathrm{p}^{\mathrm{g}}$, and for which the marginal distributions over consumption by type coincide. Note that the equality of the marginal distributions of consumption by type will imply that the payoffs to the agent under the original allocation and the constructed allocation are the same and that the resource balance condition is satisfied in the other economy. If this constructed allocation was not a solution to the agents' problems, then it could not have been 
a solution to the agents' problems in the original economy. Hence, by contradiction, the constructed allocation is a solution to the agents' problems.

First define

$$
H(p, i, w)=\left\{c \in C: p_{s}(c)-p \cdot e^{i}=w\right\}
$$

Now, given an allocation for an agent of type $\mathrm{i}$ in one economy, we can construct an equivalent allocation for this agent in the other as follows: Given $\mathrm{a}^{\mathrm{i}}$ we can construct $\mathrm{x}^{\mathrm{i}}$ by setting

$$
x_{s}^{i}(d c)=g_{i}(d c) \text { and } x_{s^{\prime}}^{i}(C)=0 .
$$

Given $\mathrm{x}^{\mathrm{i}}$ and $\mathrm{p}^{\mathrm{l}}$, we can construct $\mathrm{g}^{\mathrm{i}}$ by requiring that

$$
\mathrm{g}_{\mathrm{i}}\left(\mathrm{Q}_{\mathrm{w}} \times \mathrm{Q}_{\mathrm{c}}\right)=\mathrm{x}_{\mathrm{s}}^{\mathrm{i}}\left(H\left(\mathrm{p}^{\ell}, \mathrm{i}, \mathrm{Q}_{\mathrm{w}}\right) \cap \mathrm{Q}_{\mathrm{c}}\right) \text { for all } \mathrm{Q}_{\mathrm{w}} \subseteq \mathrm{W} \text { and } \mathrm{Q}_{\mathrm{c}} \subseteq \mathrm{C} \text {. }
$$

Note that we have constructed $\mathrm{g}^{\mathrm{i}}$ from $\mathrm{x}^{\mathrm{i}}$ and $\mathrm{p}^{\mathrm{l}}$ in such a way that condition $(\mathrm{i}, 2)$ of the gambling economy is satisfied.

Next, we will verify that the constructed allocation satisfies the individual's budget constraint if the original allocation did in the original economy. Note that if $g^{i}$ satisfies conditions $(i, 1)$ and $(i, 2)$ of a gambling equilibrium, then

$$
\iint p_{s}(c) g_{i}(d c \mid w) g^{i}(d w) \leq \int w g^{i}(d w)+p \cdot e^{i} \leq p \cdot e^{i}
$$

which implies that

$$
\int p_{s}(c) g_{i}(d c) \leq p \cdot e^{i}
$$

Then, note that from condition (i) of a competitive equilibrium in the lottery economy, $x^{i}$ satisfies

$$
\int\left[p_{s}(c)-p \cdot e^{i}\right] d x^{i} \leq 0
$$

which implies that

$$
\int w x^{i}(H(p, i, d w)) \leq 0 \text {. }
$$


The equivalence between set of equilibrium allocations of the gambling economy and the lottery economy makes clear two points. First, there are no gains to allowing for additional trading opportunities after the markets have shut in either of our economies. This point seems obvious with regard to our gambling economy since the final allocation is a deterministic competitive equilibrium given the allocation of wealth that emerges from the first stage. In private information lottery economies, such as Prescott and Townsend (1984b), this need not be the case (see Kahn and Mukerjee 1992 for a discussion of this issue), but absent private information it is. 


\section{References}

Bewley, T. (1972): “Existence of Equilibria in Economies With Infinitely Many Commodities," Journal of Economic Theory, 4(3), 514-540.

Cole, H. (1989): “General Competitive Analysis in an Economy With Private Information: Comment," International Economic Review, 30(1), 249-252.

Cole, H., Mailath, G. and Postlewaite, A. (1993): "Bargaining and Investment in a Two-Sided Matching Model," Memo.

Cornes, R. and Sandler, T. (1886): The Theory of Externalities, Public Goods, and Club Goods. Cambridge, England: Cambridge University Press.

Debreu, G. (1954): "Valuation Equilibrium and Pareto Optimum," Proceedings of the National Academy of Sciences of the U.S.A., 40, 588-592.

Foley, D. (1970): "Lindahl's Solution and the Core of an Economy With Public Goods," Econometrica, 38, 66-72.

Jones, L. (1984): “A Competitive Model of Commodity Differentiation," Econometrica, 52, 507-530.

Hansen, G. (1985): “Indivisible Labor and the Business Cycle,” Journal of Monetary Economics, $16,309-328$.

Hart, O. D. (1979): “Monopolistic Competition in a Large Economy With Differentiated Commodities," Review of Economic Studies, 76, 1-30.

Hornstein, A. and Prescott, E. (1993): “The Plant and the Firm in General Equilibrium Theory," in General Equilibrium and Growth: The Legacy of Lionel Mckenzie, ed. by R. Becker, M. Boldrin, R. Jones, and W. Thomson. New York: Academic Press. 
Kahn, C. and Mookerjee, D. (1992): "Optimal Incentives for Agents with Side Contracting Opportunities," Mimeo.

Lindahl, E. (1919): "Just Taxation: A Positive Solution," in Classics in the Theory of Public Finance, ed. by R. Musgrave and A. Peacock. London: Macmillan, 1958.

Stokey, N. and Lucas, R. (1989): Recursive Methods in Economic Dynamics. Cambridge: Harvard University Press.

Mas Colell, A. (1975): “A Model of Equilibria With Differentiated Commodities," Journal of Mathematical Economics, 2, 263-295.

McKenzie, L. (DATE): “The Classical Theorem of Existence of Competitive Equilibrium,” Econometrica, 49(4), 819-841.

Osborne, M. and Rubinstein, A. (1990): Bargaining and Markets. New York: Academic Press. Prescott, E. and Rios Rull, J. V. (1992): “Classical Analysis of Economies With Islands,” Journal of Economic Theory, 57(1), 73-98.

Prescott, E. and Townsend, R. (1984a): "Pareto Optima and Competitive Equilibria with Adverse Selection and Moral Hazard," Econometrica, 52(1), 21-45.

Prescott, E. and Townsend, R. (1984b): “General Competitive Analysis in an Economy with Private Information," International Economic Review, 25(1), 1-20.

Rogerson, R. (1984): “Topics in the Theory of Labor Markets.” Unpublished Ph.D. Dissertation, University of Minnesota.

Rogerson, R. (1988): “Indivisible Lábor, Lotteries, and Equilibrium," Journal of Monetary Economics, 21, 3-16.

Roth, A. and Sotomayor, O. (1990): Two-Sided Matching Models: A Study in Game-Theoretic Modeling and Analysis. New York: Cambridge University Press. 
Sandler, T. and Tschirhart, J. (1980): "The Economic Theory of Clubs: An Evaluative Survey," Journal of Economic Literature, 18, 1481-1521.

Scotchmer, S. (1985): “Profit-Maximizing Clubs,” Journal of Public Economics, 27, 25-45.

Scotchmer, S. and Wooders, M. (1987): "Competitive Equilibrium and the Core in Club Economies With Anonymous Crowding," Journal of Public Economics, 34, 159-173. 
Figure 1

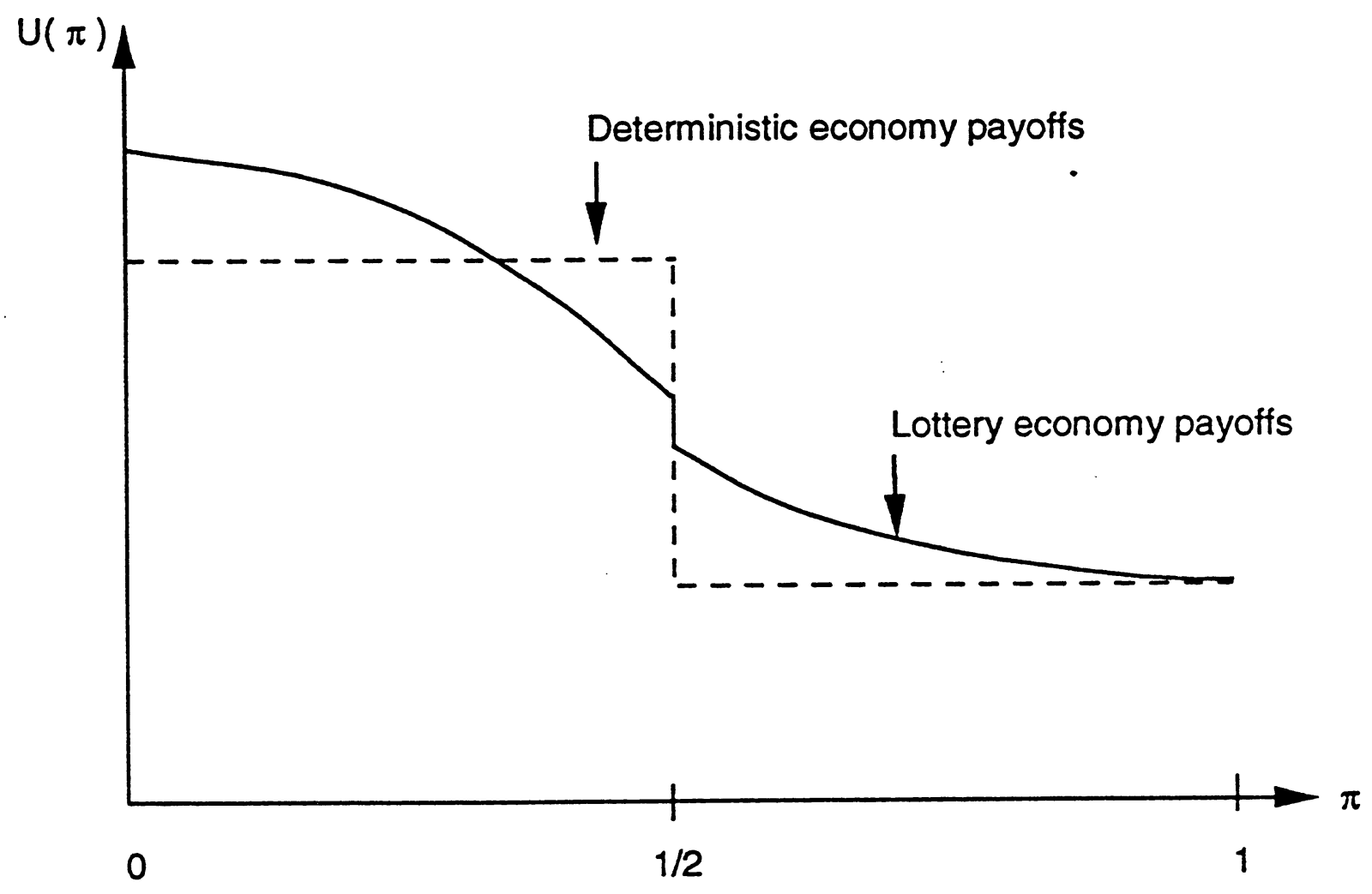


. 